\title{
Searching for Value in the Wastelands of Commodity Fetishism
}

\author{
Robert Goldman, Andrew Miller
}

Even as the dust of the 2008 global financial crisis settled into a grim recession, a majority of advertising discourses continued to herald landscapes of well-being produced by corporate technologies of speed and rationality set against a backdrop of an invisible no-hands market. We have long since become culturally accustomed to advertising narratives that depict technologies and commodities, and not necessarily people, as the key sources of productivity and value. During recent decades, the hegemonic tilt of both corporate and commodity advertising has exalted computerized technologies and financial capital as the essential sources of value and well-being. And of course, the whole of the advertising system is organized to lend value to brands-one cannot successfully market consumer commodities in global markets without a brand identity. In a postmodern ad world, a strong case can be made that the source of value has been relocated to the semiotic organization of visual symbols. With globalization, the separation of production from consumption has widened, at the same time that the pressure on commodity advertising has escalated to infuse brand, or sign, value into its products. The sum of this is that advertising routinely divorces commodities from their producers - as a discourse, commodity advertising is prone to reproducing ideologies of commodity reification.

But hegemonic discourses, by their very nature, exist in a force field of contestation and contradiction. In order to affirm the value of brands in commodity relations, the vast majority of advertising represses most of the social and cultural "effects" produced by a commodity system, as well as, of course, repressing key contradictions of structural inequality in the global capitalist system.

But in an oversaturated advertising world where so many advertisers mimic one another, this leaves open a space for a few advertisers who seek to gain advantage by differentiating their brands — making them stand out—by raising otherwise repressed questions about the relationship between "value" and human "labor." What constitutes value, and where does it come from? What happens when soft questions about the meaningfulness of labor reappear on the screen of the spectacle? We begin by looking at how the subject of value, and what constitutes it, flows throughout advertising as a form of tacit knowledge.

\section{The Question of Value in Advertisements}

Advertising presides over the production of semiotic exchange values — sign values — within the globalizing commodity system. This system of commodified semiotics has evolved into a primary axis for differentiating branded consumer goods under the regime of global capital.

When we look at advertisements we see discursive instruments aimed at socially constructing value. Concepts of value are almost always embedded in the structure, as well as in the interpretation, of ads. The semiotics of value is so intrinsic to contemporary advertising practice that we rarely take notice that the premise of valuation-which the ad hopes to lead us to validate-is the subtext of most ads. The average consumer ad has been devised according to a formula for creating structural equations aimed at bolstering a value proposition. As such, advertising constitutes 
a technological form for reproducing what Jean Baudrillard referred to as "the structural law of value," a stage of value construction that rests on referential fluidity. The matter, in a nutshell, is that value can no longer be considered a stable or durable entity: indeed, as Capital continues to mature, the half-life of "value" becomes more and more fleeting, requiring that more value, new value, amplified value, be ceaselessly assembled to replace that which decays and falls out of orbit. In short, advertising is an institution charged with the task of conjuring up value semiotically, even though the process of accomplishing this simultaneously undermines this goal by contributing to a clutter of signs and values.

Ads semiotically frame the cultural production of value. Lending additional value to a commodity via advertising is the goal, but not all can succeed in a competitive sign economy. In competitive markets, commodities without a memorable sign value are at a significant disadvantage in staying price competitive and offsetting the erosion of price margins. Along with cutting production costs through global supply chains and the outsourcing of labor, semiotically adding value to brands has become a basic tool in trying to offset the tendency for rates of profit to decline as markets mature. This process requires mining the value of already existing signifieds: those signifieds may be drawn from a celebrity athlete's perceived market value, or from the ideological category of "Moms" who sacrifice for their kids. The potential list of signifieds could go on ad infinitum, although in practice the tendency is to overconcentrate on a relative few: e.g., when LeBron James wins championships, the brand bandwagon effect launches into frenzied repetition.

Sign value can be thought of in terms of a few ideal types; in practice, of course, there is a good deal of overlap. One commonplace method sets up a framework for constructing exchange value by placing a good or service into equivalence with another value-permitting value to be expressed as an exchange value. At the level of content, the range of signifiers and signifieds may seem nearly infinite, but structurally this approach obeys a more limited series of semiotic maneuvers (see Williamson, 1978). For instance, a shampoo might be valued by the number of admiring glances its models draw, so that admiring glances become the currency behind the currency — this Baudrillard (1981) called symbolic exchange value. In the currency of sign values, signifiers (the carriers of meanings) and signifieds (the meanings) must be unhinged from wider meanings systems so that they can be recombined and modified in service of the Brand value. Another approach translates the meaning of a commodity into symbolic value-the classic example is how diamonds have been made to symbolize eternal love; or how Nike has come to symbolize a philosophy of everyday life ("Just do it"). A third route involves what Baudrillard (1981) called "the sign value of an object; its value within a system of objects." This is most obvious in what we call "sign wars" ads, ads in which one brand's logo bests another.

In the current stage of commodity-sign capitalism, the brand must function as a meta-sign. That is to say, the leading brands are leading brands because they are able to unify under their logo a whole range of meanings; for example the Nike swoosh gathers and unifies a range of signifiers and signifieds under its umbrella. The Brand as meta-sign

"gathers" a multiplicity of meanings into a single Name and thus "opens up" a whole world. Levi's does not just point towards the alleged properties of a pair of jeans, it sustains a whole world of meaning(s) which provides the background against which we experience what it is to wear jeans, the "world" which comes with wearing jeans" (Slavoj Žižek, 2010:356-357).

The Levi's "Go Forth to Work" campaign, which we shall discuss in detail, fashioned together images of Braddock, Pennsylvania to summon forth "a whole world of meaning(s)." Levi's history of trying to ontologically frame "real spaces" goes back to the early 1980s and the "Levi's 501 Blues" campaign that sought to tap into the musical texture of urban Blues to locate an aura or climate of individual authenticity. That 1980s' campaign cultivated a stance of self-awareness about the ontology of everyday life as expressed via the TV commercial itselfit marked a postmodern turn in advertising, a "knowing wink" about commodity identities in the age of the simulacra (Goldman and Papson, 1991). The campaign constructed hyperreal signifiers of realism, wrapped in a self-referential awareness about the nature of advertising itself. As a central player in those early efforts (1984-1987) at constructing a simulacrum of the real, Levi's sought to position itself as a space of authenticity that ran counter to the rest of the world of commodity signs with their admonitions that one could find a prefabricated authenticity by consuming a particular brand of jeans or soda pop or cars. The 1984-1987 Levi's campaigns represented a shift in the landscape of advertising - the question of what constitutes "the real" when passed through the lenses of the media was now permanently a part of a wider cultural discourse. But the knowing wink had a self-fulfilling dimension: viewers hailed by "the knowing wink" soon learned to be wary of its claims, as well as its many imitators. Cynicism continued to evolve as the spectator's armor of protection. 
The current phase of this "semiotic capitalism" has been heavily influenced by the shift to digital technologies that are linked to the rise of social media. Digital technologies streamline the processes of fracturing meaning into semiotic particles so that they can be recombined to form novel [read, differentiated] meanings. Exposure increases, as does the speed and the frequency of delivery of commodity sign formulas. When joined to social media this leads to heightened awareness of ads and a percentage of viewers grow restive, cynical and resistant about their participation in this sign economy.

If every advertiser used the same formulas, the same signifiers, and the same signifieds, the clutter would make it even more difficult to differentiate the sign values they concoct and promote. So advertisers adopt a variety of strategies in how they set up their valuation equations - the appropriation of a cultural value is one frequent starting point; followed by simple semiotic comparisons or contrasts that place the preferred cultural value in relation to the brand's value. This dialectic of differentiation and mimetic repetition defines the search for value amongst advertisers, so that the same prosaic tropes frequently repeat themselves until they burn out from overuse-like the way that too many beer ads juxtapose having to choose between a beautiful woman or a brand-name beer. This tired advertising joke invariably ends with surprise, surprise, the male selecting the value of the beer brand over the value of sex. The logic is that if being with a beautiful woman is seen as having value in our culture, then this beer must really be worth purchasing. But if desire is the true metric of value in a market society, then this discursive game must be replayed endlessly because evanescent desire, under this system, itself needs to be reproduced endlessly. Value in this light is always contestable, because it is always a matter of semiotic assembly and disassembly.[1] Today, the very fabrication of semiotic superiority has become the subject of mockery in still other ads. To illustrate, Geico ran a 2012 ad campaign playing on the ubiquitous taste test - a simple device for demonstrating the semiotic superiority of brand X over brand Y-by staging a "car insurance taste test" with good-natured volunteers who sip small cups of drink representing Geico and "Other" (its competitor). After each participant prefers the taste of Geico over the taste of the "Other" (accompanied by grimacing facial gestures) the joke is completed when they are asked if this was "your first insurance taste test?" to which they respond with dumbfounded looks.

We are intrigued by what we might learn from those ads that incorporate self-reflection about where value comes from into both the narrative frame and the theme of the ad. Why bother to raise the question of value from the tacit to the manifest level? Let us begin with two ads that explicitly draw attention to what constitutes value in order to affirm the value of the particular advertised good. The first ad for a highly disposable commodity (gum) seems to be set up as a joke, while the second ad for hopefully the most durable commodity that we will purchase (a house), a commodity that functions as the primary investment vehicle for millions of people, presents itself as a folksy-ministerial homily that edifies the true bedrock of value-the wealth of uncommodified personal experiences, the part that MasterCard calls "priceless."

A 2010 Trident campaign jokingly imagined for viewers a world in which people would want to get paid with Trident gum. Despite the fact that the ad's premise confuses currency as a medium of exchange with the accumulation and consumption of objects of miniscule value, the silliness briefly exposes the arbitrariness of value, and the way it is represented. Set in a suburban middle class home, a stereotypical father comes home from work to his family.

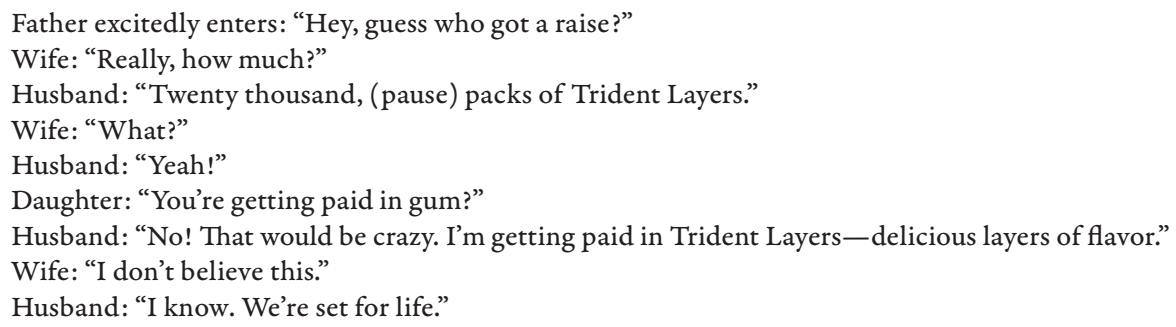

The ad's joke structure acknowledges anxieties about stagnant wages and "underwater" mortgages, and the doubts thus triggered about what constitutes a secure, reliable basis for value in a world beset by volatile upheavals where value invariably turns out to be much more insubstantial than advertised. The pragmatic wife (who is presumably responsible for managing the household budget) immediately registers her incredulity at her husband's foolishness. When even his daughter questions the rationality of being paid in gum, the father responds with the ad's crucial line in defining value: "No! That would be crazy. I'm getting paid in Trident Layers." Had it been generic commodity gum, yeah, this would not represent a fair price, but because Trident Layers are supposedly unique and deliciously flavorful (a proprietary commodity), their value instead becomes elevated into something materially substantial. Although 
structured as a joke about the contemporary compensation for the performance of labor, like most advertising jokes it does not ask us to dwell long, or deeply, about matters of exploitation accomplished through this streamlining of the commodity-money-commodity circuit of relations that Marx explored. Perhaps a more daring campaign would have included a follow-up ad that featured the father trying to pay his mortgage in Trident Layers.

A 2012 Coldwell Banker ad performs a more sweetly nostalgic account of "what defines value."

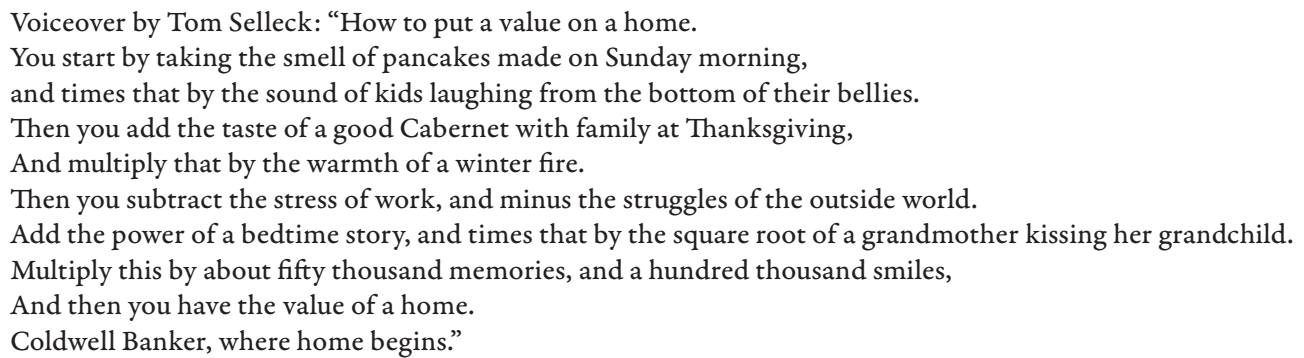

With scene after scene of adorable laughing children, this ad operates on shameless appropriation of the value of family in American mythology. The nostalgic desire for an imaginary family of yore, a comfortable family unit that encompasses multigenerational emotional commitments and celebrates the traditions, becomes a selling point. In consumer ideologies, labor has long since been erased as the site of meaningful self-production, and indeed, as a site of necessity. Instead, the house emerged as both the new fountain of value production and as the preeminent site of meaningfulness. During the boom years, it did indeed seem as if the capitalist Holy Grail had been achieved through the magic of financial instruments that appeared to permit the multiplication of value without the necessity of wage labor. Home values skyrocketed, as did second mortgages to cash in on disposable income to keep the consumer pipeline streaming during an era of stagnant wages (Brenner, 2004). And then the music stopped and a lot of folks lost all of that imaginary value. The reverberations of the valuation bubbles — the housing bubble, then the derivatives bubble, and the financial crisis that ensued-have however raised anew concerns about the relationship between price and value. The Coldwell Banker ad accomplishes a sleight-of-hand as it redirects reflection away from the housing bubble with its attendant questions on how to distinguish 'real' value from the puffery of market illusions. By placing all this within the language of mathematical formulas and equations, it reminds us that emotionladen sets of calculations represent the true socially and culturally constructed calculus of value.

\section{Labor, Value \& the Search for Meaning in the Spectacle of Commodity Fetishism}

Representations of labor made a stealthy reappearance in the world of television advertising following the 2008 financial crisis. While this makes sense, given that recessions prompt messages suitable for the times, why have previous recessions not rattled the soft convictions of advertising discourse quite so much? For decades, Labor has registered as little more than an invisible assumption in consumer-goods ads, the necessary but tacitly invisible prerequisite to being able to consume. As anticipated by Guy Debord, Jean Baudrillard and Wolfgang Fritz Haug, commodity fetishism jumped the fence from production relations to consumption relations in the second half of the 20 th century.

So why would a self-reflexive attitude about labor reappear in the last few years? And when we say 'reappear,' we are aware that this represents but a modest cameo disturbance in the overall force field of representations produced by advertisers. Still, reading the more typical representations in terms of such minority texts permits us to "overturn the hierarchy at a given moment" (Derrida, 1981:41).

Though representations of labor may have disappeared over the years in consumer-goods ads, representations of employees have never quite disappeared in corporate image ads. Their appearance in corporate ads over the last decade is usually included to indicate how happily productive the firm is, or how up-to-date technologies harmonize with a contented and dedicated workforce. With the possible exception of ads for online employment agencies (e.g., Monster.com) few ads, however, actually raise questions about the meaning of a job or about its relation to the production of value.

Two consumer campaigns from 2010 raised questions about the relationship between meaningful labor and 
what is valuable to us. At first glance, these campaigns for Volkswagen Jetta and Levi's 501 jeans appear to share little in common. The Volkswagen campaign for the 2011 Jetta model featured ads that called attention to commodity fetishism in relation to two different kinds of labor and two different motivations for labor. In the Jetta ads, however, the text takes the side of the consumer. In the first ad, titled 'Moonlighting,' the laborer and the consumer are the same person, a reminder that wage labor is still necessary for most of us if we wish to make expenditures for durable goods like aesthetically pleasing automobiles. Put another way, labor is treated as an activity devoid of meaning, but merely as a means to the end of consumption. The second ad, entitled 'Dream Team,' addresses labor from the side of an engineering team that designed the new Jetta-it offers a winking joke about the tragedy of commodity fetishism if one actually takes pride, or seeks meaning, in one's work. It ends by reaffirming the goal of commodity fetishism as price fetishism because price fetishism always serves the consumer.

There is no joke in the Levi's 'Braddock' campaign, which included a print campaign, television ads, and a series of eleven documentary-style YouTube videos that dwelt on individual personalities trying to make it in Braddock, Pennsylvania, a long-suffering rust-belt city. These videos raise questions about the value of labor, about its meaningfulness, and possibly about the resurrection of an American work ethic in order to find fulfillment, community and authenticity.

\section{| Volkswagen Jetta Tells Fetishism Jokes}

Volkswagen Jetta ads from 2010 affirm a familiar ideological ring-the greater good when it comes to conflicting interests between consumers and workers should always go to the side of consumers. An ad titled 'Moonlighting' actually situates the balance between the consumer's interest and the worker's interest within the same person, a worker who is willing to suffer in order to make his consumer self happy. In a sense the ad asks 'what is the value of alienated labor?' Though this yields a familiar advertising conclusion, the path of the narrative and how it is told reveals something more. Viewers are introduced to a young man who works as a hospital orderly (his day job), bureaucratically organized and regulated. The narrative is established in the opening scenes as the orderly looks out a window and becomes entranced by a billboard that pictorially envisions the new Jetta in the same way a glamorous model might appear in a Victoria's Secret ad. This billboard image makes no mention of price; it is a tease that tempts him (seduces) with its allure. He tears the same ad from a newspaper and mounts it, like a centerfold, next to him to keep himself motivated while he works. As the ad plays out it evolves into a discourse about how much labor is required to acquire this car, even though the ad treats the car itself almost entirely as a commodity fetish. If the car's value as a material product hinges on the exercise of labor by autoworkers, this remains fully out of sight and out of consciousness. Instead the ad mirrors an oddly non-reflexive self-reflection on the relationship between the advertising of desire and the consuming subject. It is hard to imagine a more one-dimensional account of advertising's seductive powers: to wit, the car's visual image immediately excites his desire to possess it!

Behind the images, the story is narrated by the lyrics of a five-decades-old country song by Wynn Stewart, "Another Day, Another Dollar." Though it is a rhythmically and harmonically upbeat song about the dulling rhythms and routines of everyday working class life, the lyrics convey a sobering dose of fatalism, inevitability and sacrifice. Written in 1962, the song exemplifies the Bakersfield sound, country music for the western white working class of that era.

\footnotetext{
Another day another dollar, daylight comes I'm on my way.

Another day another dollar, workin' my whole life away.

The boss told me I'd get paid weekly and that's exactly how I'm paid.

Another day another dollar, workin' my whole life away.

Another day another dollar, daylight comes I'm on my way.

Another day another dollar, workin' my whole life away.

My family is my thanksgiving, I love them more and more each day.

And they're the reason I keep living and working my whole life away.

Another day another dollar, daylight comes I'm on my way.

Another day another dollar, workin' my whole life away.

Workin' my whole life away.
}

Considering that this is an ad, the lyrics are remarkably unedited until the lines about "My family is my thanksgiving, 
I love 'em more and more each day. And they're the reason I keep living and working my whole life away." Those lines are omitted in the ad. The reason given in the original song for enduring the loss of freedom-the grind, the bosses, the weekly wage (and not a salary_-was because of love of family. By contrast, in the ad, love of family has been replaced as the primary motivation by the individual's desire to own an aesthetically pleasing object of desire. The song reaffirmed an echo of the masculine pride that had been surrendered to the hourly wage, by recasting this loss of manhood in the workplace within a patriarchal, and romanticized, image of loving [taking care of] one's family. In the Jetta ad, even that patriarchal pride seems to have melted away-indeed, the jobs he accepts all require that he degrade himself in some way-in order to serve the engines of his own desire. His desire to possess the car seems to rest on a revival of deferred gratification and a willingness to endure suffering and humiliation for a reward. Thus motivated and in need of "extra cash," the young man throws himself into the informal economy, taking on parttime work as a dog walker, a punching bag for a women's self-defense class, shagging golf balls, a sidewalk hotdog mascot, and a rodeo clown. He freely chooses unfreedom as a worker in order to transfer the "sign of 'freedom'... to the domain of consumption" (Baudrillard, 2005:11). As Marx observed, the freedom of wage labor was essential to the structural condition of alienation (the unfreedom) of the worker.

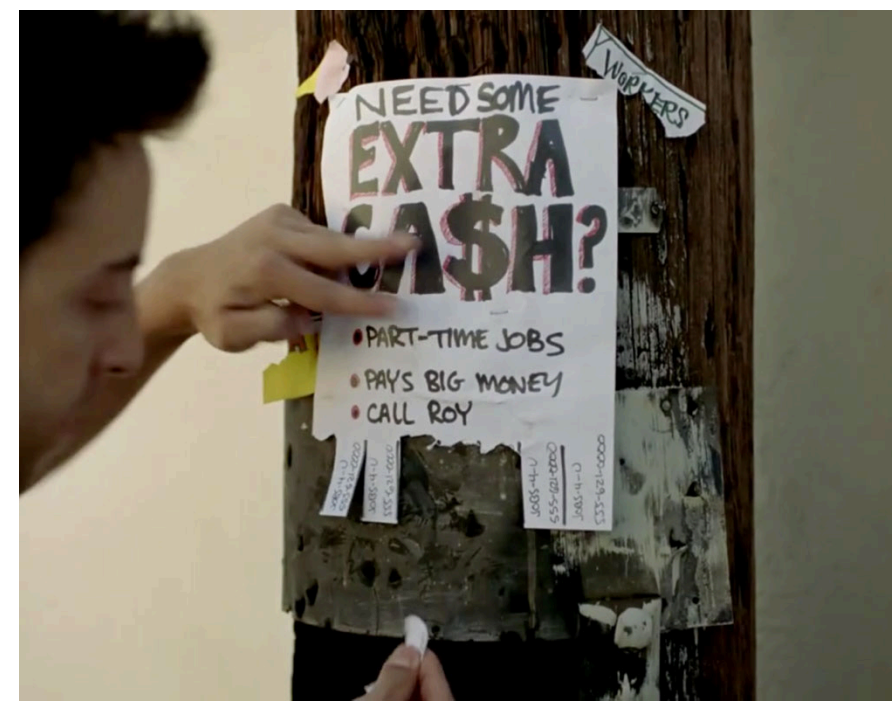

The informal economy visually symbolized.

After a quick serial survey of the many forms of degrading labor that he performs for extra cash, we see him counting his accumulating stash of money, measuring the distance from his desire. When we see him again as a hospital orderly cleaning a patient's feet, he spies an updated advertising billboard that places the price of the car next to the image. He suddenly realizes that this object of immeasurable desire is so affordable that he can now purchase two with his accumulated cash. Upon seeing this new information about the car's price, he drops his cleaning bucket to the floor; by the time the bucket hits the ground, the scene and the meaning of the bucket transform from a signifier of workday drudgery to his driveway where the bucket's purpose is for lovingly washing his two new VW Jetta vehicles — each now identified by vanity license plates, "MINE" and "MINE 2."

A second ad for the VW Jetta was titled "The Dream Team." Set to bold, energetic music that builds toward a goal, the narrative arc of the first half of the ad tells a story of dedicated and highly skilled engineers and designers working single-mindedly, putting in hours around the clock to accomplish the ideal engineering of the perfect personal vehicle. The crucial labor shown here is the creative labor of designers and engineers. Halfway through the ad the car is showcased at VW headquarters to enthusiastic applause and recognition. For a split second these fashion designers of the car universe receive the acclaim they seek for their labors. The celebration continues in the following scene with the public debut of the car staged as a spectacle-where the most important feature of the car is its ostensible visual beauty and where its fetish value matters most. But when the price is announced at $\$ 15,995$ the team of designers turns emotionally crestfallen before sinking into despair, devastated by how cheap the product of their labor has been made. Instead of this vision of beauty proving their talent, it replaces them. All their hard work and the perfection they have engineered are devalued in this moment. This twist captures what Richard Sennett refers 
to as "talent and the specter of uselessness" (Sennett, 2007:83). Their talent, after all, does not make them special or worthy of honor as they had hoped, but rather replaceable and dispensable.

Though this is great news for you, the potential consumer, ("great for the price of good"), the creators experience a loss of meaning-with their identities hinged to the product of their labors, their characters react to this price depreciation as a sign of their own deflated significance. How then can so much value be had without exploiting some part of the labor process? By replacing labor with technological automation? Or by reminding us that there is no solid footing for even talented labor in liquid modernity (Bauman, 2000)? The ad treats the dream team's experience of creative alienation as a joke, for their alienation benefits the consumer in lower prices. What remains tacit is that their alienation also benefits the capitalist's bottom line.

Ads work best when they address the task of conceptualizing the value of a branded good or service. A tacit conception of value as worth is the thing that premises the price of said goods. Historically, brand goods advertising eschewed the explicit matter of price: that is, the ads aimed at bolstering the social, cultural, or economic reasons for having the commodity. That changed with the advent of Wal-Mart and other giant retailers, where a competitive emphasis on low prices in their advertising has for all practical concerns made price and value the same thing. Effacing value is however not a viable long-range strategy. By continuously lowering prices, the Wal-Marts of the world run headlong into the potential devaluation of value. That is, the distinction between value and price-or between use value and exchange value-begins to disappear, and without that distinction the meaning of value begins to wane. This is precisely what the Volkswagen joke is about-the hegemony of price eclipses quaint classical conceptions of the meaningfulness of labor and the durability of value.

Running opposite the Volkswagen discourse on labor and value is the Levi's "Ready to Work" campaign that posits that honest labor is its own reward and the only way to rebuild institutions that have broken down. In the Levi's universe of Braddock, labor that has purpose leads to a vision of re-centering the self and community-of a self that is not immaterial and seeks certainty about one's sense of self being grounded in something social.

\section{Looking for Meaning at the Landfill}

Catalyzed by inflated asset value bubbles, the post-2008 recession came with double-digit unemployment rates coupled with continued employment at stagnant wages. The recession and its impact on youth entering a shaky labor market were inextricably bound to irrational exuberance and its manic-depressive aftermath. In the midst of this, those entering the first decade of their "careers" confronted a sobering moment of reflection. With the pursuit of "career" already in tatters, [2] many young people had become disillusioned with the prospects of a trail of corporate jobs coupled with the extension of the same old consumerism that had already lost its allure. From the perspective of marketers seeking to reconnect with this youthful demographic, this crisis of motivation looks like a collective search for authenticity situated against a global financial system that accommodates artificially inflated values while marginalizing and depreciating concrete sources of value, namely manual labor.

In the Levi's "Ready to Work" campaign, our theoretical question coincides with their practical task: how can sources of value be relocated or articulated in ways that seem achievable? In cultural, rather than political-economic terms, something like Marx's labor theory of value seemed more necessary than ever. Could the revival of value be resituated in the immediacy of labor, while severing the labor theory of value from its anti-capitalist implications? The Levi's campaign opens a window into how this curious historical sensibility could be represented. Our reading of the Levi's campaign interprets the campaign's representations against the backdrop of global capitalist social relations. We argue that the Levi's ads referenced, but did not formally acknowledge the dimension of capitalist life. As such, Levi's raised questions about labor and social equality in the decimated landscape of capitalist deindustrialization, but treated the latter primarily as a visual abstraction.

When Levi's via Wieden + Kennedy framed the sound bites collected from the young people they found in Braddock, Braddock was made to represent a space outside of the capitalist social relations that they have come to mistrust. And in truth, Braddock had really gone missing from the map of contemporary capitalism. A town left behind, where it just doesn't pay to maintain markets, Braddock had been all-but-abandoned by Capital. The era of Post-Fordist globalization signaled the death warrant for industrial manufacturing in Braddock. After the steel plants closed, unemployment drove away the population and the collapse of the retail infrastructure followed. Without a tax base, the public sector withered, and there was no money to maintain the urban infrastructure of buildings 
and streets. The real-estate market essentially collapsed, and without liquidity or capital infusions, the city decayed. What's left ranged in the ads from a few retirees who have been able to make ends meet along with the last of the middle class_ _ such as a Miss-Havisham type who sits cloistered amongst her antiques. But the ads themselves focus primarily on the new migrants to town such as a self-styled urban farmer, very serious about his mission to grow food from earth that once sat beneath the buildings of urban industrialization.

The ad's director made clear that the campaign aimed to hail their 18-to-34 audience with a focus on the theme of "authenticity." We use the category of Hipster to refer to a disunified cultural category, but one that stands out as a subset of the Millennial generational demographic that finds mainstream commodity culture unsatisfying and empty — a desert of meaning. The audience hailed in the Braddock stories runs across a number of social categoriesinterracial, local working class, former lumpenproletariat, and hipster migrants who are college educated. All of these taken together form an imagined "new working class." [3] As much middle class as working class, these groups seem to coalesce around cultural preferences, and unify in their commitment to manual labor-aimed at both demolition and rebuilding.

Font-work 101: these images convey the general theme of Levi's campaign through font use, namely the preference for that which is done-by-hand over that which can be accomplished via computer codes. Flouting kerning techniques (top) and signifying a "historical" Braddock through handwritten captioning (bottom) are two examples of how font can guide interpretation.

The 2010 Levi-Strauss "Ready to Work" campaign posed questions about the meaning and value of labor. An integrated, multi-chapter series of videos focused on the deteriorating steel town of Braddock, Pennsylvania as a specific backdrop, and a symbolic microcosm, of the devaluation of American labor, and as a home to the revival of a collective sense of spirit and meaning, manifest in urban renewal projects that invoke the forsaken value of blue-collar, manual labor-sweat equity. Throughout the series, Levis constructed montages of urban decay, postindustrial wastelands, interwoven with the faces of those who have borne witness to Braddock's history or have since migrated to the Pennsylvania mill town. Levi's framed these scenic montages with a title card that read "We Are All Workers." This title card aimed at hailing a relatively youthful totem group that identifies with the marginalized and displaced population of blue-collar workers.

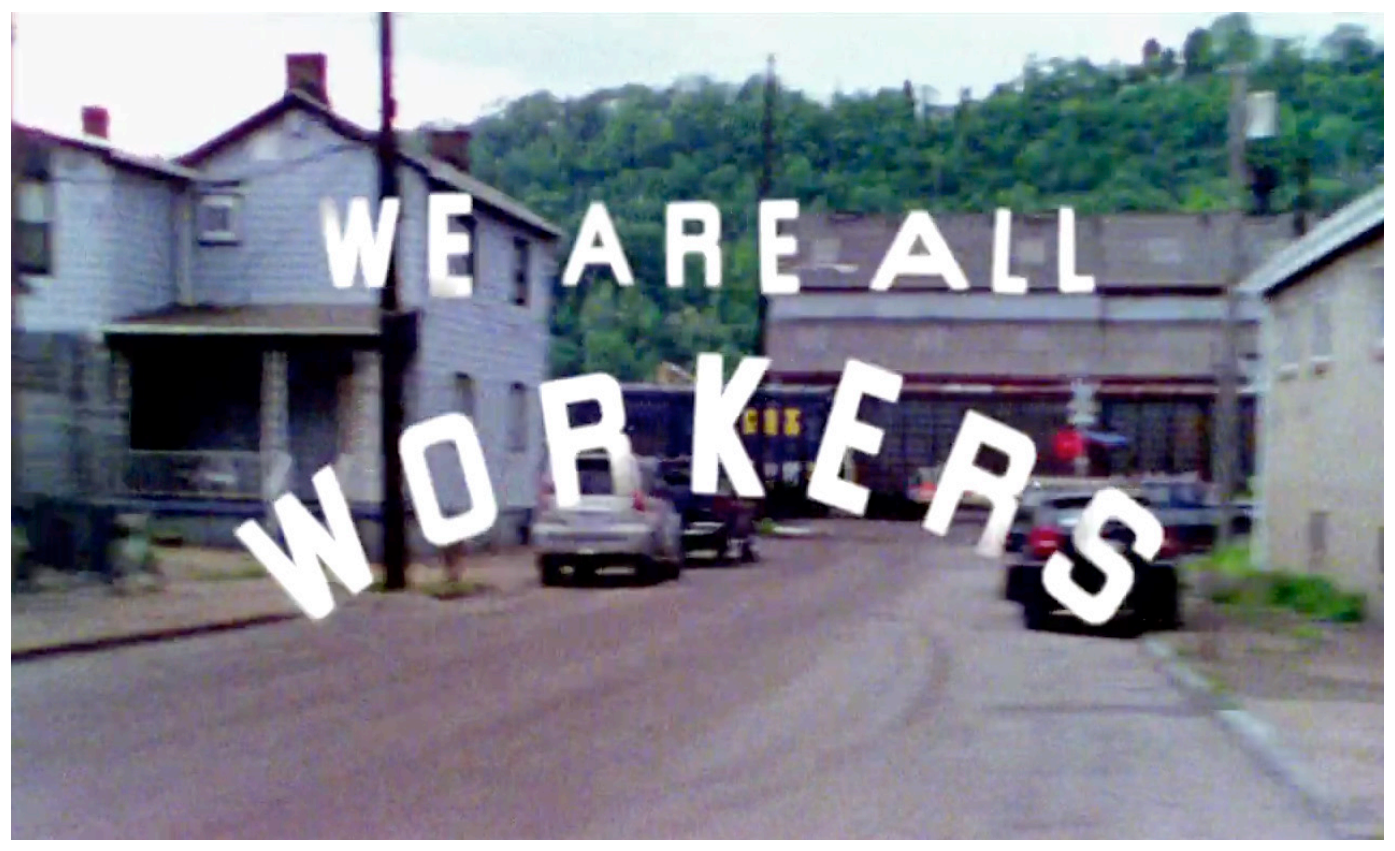

Font-work 101: these images convey the general theme of Levi's campaign through font use, namely the preference for that which is done-by-hand over that which can be accomplished via computer codes. Flouting kerning techniques (top) and signifying a "historical" Braddock through handwritten captioning (bottom) are two examples of how font can guide interpretation. 


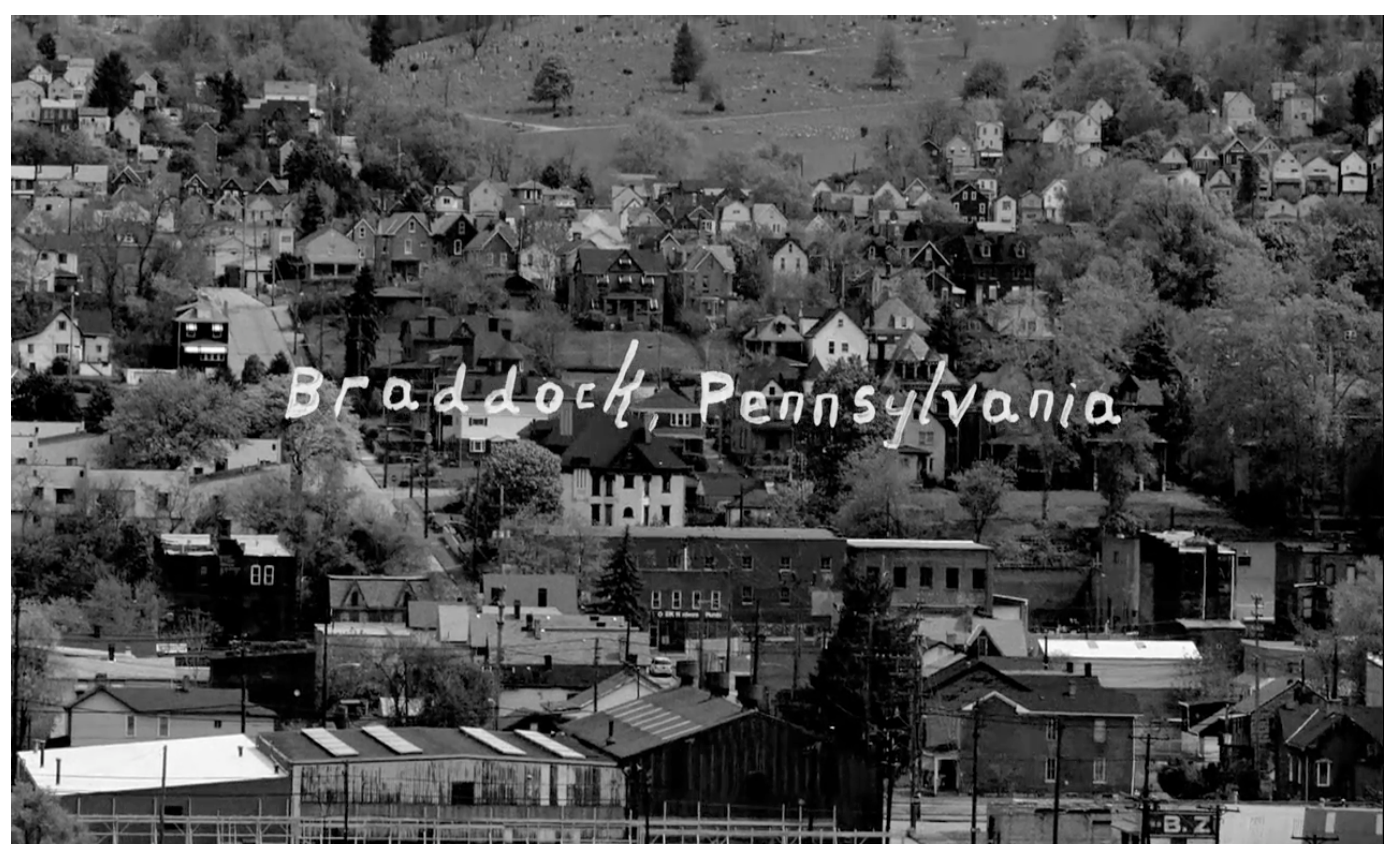

This title card consisted of slightly mismatched felt letters akin to those amateurishly placed (that is, they are not perfectly spaced) on little league baseball jerseys. Considerable font-work has been undertaken to fashion a "handmade" sign — the letters are of varied sizes and spacing. In the advertising world, where so much signification has been compressed into the association of a font with a brand, this stylized way of differentiating the totemic heading, "WE ARE ALL WORKERS" can be seen as a signifying strategy for accentuating various possible meanings: "Imperfect," "Working Class," "Workers with Limited Resources," all of which allude to pride in the flawed, but nevertheless vulnerable sources of otherwise forgotten labor that unite this newly reestablished collective.

Levi's undertook this campaign in the midst of a crisis of the global capitalist system. This pivotal historical moment may be attributed, at least partly, to globalization and the decline of the American work ethic, once mythologized by an upwardly mobile manual-laboring class that has been supplanted by the rise of immaterial labor as a fresh source of value for capitalist accumulation. Braddock, PA signifies a rustbelt town left behind in the information age, an industry-heavy town that failed to adapt to the post-Fordist standards of production. Indeed, as a long-time Braddock resident laments, "I remember when Braddock started to change, not because Braddock changed - the whole world was changing." This helpless recollection speaks about economic, social, and political restructurings of a globalizing capitalist system that sent manufacturing chasing cheap labor elsewhere, while devaluing blue-collar labor. In other words, the shift from a Fordist economy, centered on a productionist, blue-collar working class, to post-Fordism, where immaterial labor within a flexible, knowledge- and communication-based economy generates higher forms of value by catering to multinational consumer capitalism and expanding lucrative financial markets (Hardt \& Negri 2000). The Levi's campaign, then, sought to rekindle the ideals of value that are inextricably bound to the American work ethic and manifest in manual labor, but which have since been displaced by intellectual and immaterial labor in recent decades.

Before going further, while we refer to the Levi's campaign, their advertising agency — Wieden+Kennedy—also played a major role in shaping the campaign philosophically. It is particularly noteworthy that Wieden+Kennedy also sculpted the Chrysler ad campaign that culminated with the "Halftime in America" ad during the 2012 Superbowl. The Chrysler campaign hailed the collective solidarity of those who identify with the United States, and it did so with an inspirational narrative about making an economic recovery through teamwork and hard work. In both campaigns $\mathrm{W}+\mathrm{K}$ has constructed redemption and revival stories. At first blush, the Chrysler campaign seems more direct about "our" economic and political circumstances, but Chrysler's CEO stated categorically that "It was not intended to be any type of a political overture on our part. The message is sufficiently universal and neutral that it should be appealing to everybody in this country..." Here is an excerpt from Clint Eastwood's speech in the Chrysler ad: 
It's halftime in America, too. People are out of work and they're hurting. And they're all wondering what they're going to do to make a comeback. And we're all scared, because this isn't a game.

The people of Detroit know a little something about this. They almost lost everything. But we all pulled together, now Motor City is fighting again.

I've seen a lot of tough eras, a lot of downturns in my life. And, times when we didn't understand each other. It seems like we've lost our heart at times. When the fog of division, discord, and blame made it hard to see what lies ahead.

Nonetheless, Karl Rove, the right-wing political strategist, labeled this as propaganda for the Obama administration because of the auto industry bailout in 2008. The Chrysler campaign hailed audiences struggling with employment and hard times, but did so by drawing parallels between Capital and viewers under a simple narrative of adversity and the willingness to fight. In the Chrysler ad, the power of collective spirit will prevail-however, this unification of spirit occurs not by engaging the Hegelian dialectic, but by minimizing the negation of loss. By contrast, the Braddock campaign dwells on the disrepair and debris that remains of an industrial city, foregrounding the death of industrial capitalism and the lifestyle it offered. The abandoned homes of Braddock reveal a foreground littered with the scattered debris of excess packaged consumption and commodity obsolescence. Still, like the Chrysler campaign, the Braddock ads are also crafted to be inspirational, focused on a reversion to the elementary acts of hard work driven by the choices of free (frontier) men and women.

An aura of nostalgia frames the Braddock campaign (e.g., a banjo sets the tone over the opening credits of every chapter in the documentary) as an axis of revaluation. While nostalgia establishes a predominant feeling-tone of the campaign, the ads also encode sentiments of authenticity and primitivism that mimic desires amongst disenchanted youth. Set against a growing perception of commodity inauthenticity that surrounds Wall Street and consumer capitalism, the Levi's campaign seeks a dialogue with those who might sympathize with the Occupy movement. Consumer capitalism has begun to get a slightly wider negative rep amongst educated youth. The Levi's campaign presents a discursive commitment to authenticity — an authenticity defined by a landscape of rust belt ruins. It is here that we are introduced to characters who seek to find themselves in manually rebuilding a community.

\section{Revalorizing Labor}

Levi's first episode of its Braddock series, entitled "The Seeds of Change," laid the foundation for its campaign by providing a brief history of Braddock that traces its rise and fall, and, more importantly, what the town needs in order to realize any hope for prosperity again. While panning across grainy scenes of industrial decay and landfills that dot the landscape of the western Pennsylvania town, a Braddock resident shares his insight into the city's ills by explaining that "What Braddock really needs is a wave of hardworking, motivated people." Just as this is spoken, the camera cuts to a shot of a white male rolling up his denim sleeves. These frames paint a picture of what has been lost and thus what is needed to revitalize the city.

In contrast to the Volkswagen ads discussed above, which wryly mocked the lack of respect for labor and appealed to the cynicism of contemporary ideologies (Žižek, 1989), the Braddock campaign invites it audience to dwell on the labor performed with our hands. There is more than a touch of nostalgia here for a time when human labor was respected as a fundamental source of human value, and as a fundamental source of moral identity. Indeed, the campaign seeks to revalue the collective spirit of human labor by heroizing it_affording acts of deliberative, purposive manual labor their dignity. Nearly all the forms of labor that are revalued throughout the series are manual tasks such as gardening, landscaping, demolition, and construction. There is nothing high tech in these scenes. Braddock distances itself from labor at the cutting-edge of capitalism, but also declines the degradation of labor. Whereas most corporate advertising since the mid-1990s has spun tales about technologies of flexibility and speed that envision computer-enhanced capitalism as the path to prosperity, Braddock is situated at the tail end of capital's stage of flexible accumulation. Left behind by decades of post-Fordism to the forces of entropy, 90\% of Braddock "is in a landfill somewhere." Under such circumstances, Levi's continues to quote John Fetterman, Braddock's mayor, that "reinvention is our only option" for survival.

As global capitalist forces leave behind antiquated spaces, the youthful hipsters who are alienated from commodity culture and marginalized in formal labor markets look to emptied spaces such as Braddock for opportunities to make 
a mark culturally (paradise might be an art renaissance) and materially (restoring properties and buildings that are ready for the junk heap). Levi's translates this into new "frontiers" where the frontier is a space that is structurally open, whether that means rebuilding houses abandoned to the decay of neglect and time, or putting in the raised beds of an urban farm on a site that formerly held dilapidated buildings. In hard times it means the opportunity to work and to make meaning through the exercise of one's labors.

Marshall, the self-styled urban farmer, seems intent on reconnecting with Nature à la Thoreau-he is not just doing organic farming, he is doing it all by hand. And he is doing it on the former site of industrial capitalism. This is his frontier, abandoned empty lots that can become an "opportunity" for individual visions and passions. Focused on the negation of industrialization, he cultivates his perfect anti-modern space, free from the intrusions of oppressive workplace authority. He represents the newfound ideological enthusiasm for urban farming — all the buzzwords are here: sustainable, local, fresh, and organic. More romanticist than capitalist in his motivations - this is his spirituality: he finds meaning in this communion between himself and the earth, nothing else mediating the activity. He is "mostly just staring at the ground," intent on the micro tasks in front of him, the raised beds, because it is in these raised beds that he has found his purpose (calling).

Especially in their television ad, Levi's tries to re-establish an aura around manual labor. In a way that seems oddly reminiscent of attempts to replicate "aura" around historical theme parks, the Levi's ads turn the tools of hyperrealism to simulate the grittiness of a radically depressed space, in turn opening up a radically new space for meaning, for the purposes of radical social change or, on the other end of the spectrum, for new outlets for capitalist penetration. In the case of the "Ready to Work" campaign, the latter applies: the re-enchantment of aura around manual labor forms a signifier/signified about which some portion of the 18-to-34 consumer demographic can rally.

Further, to continue with language apropos of geography, the ad distances Braddock from the discourses of late capitalism that privilege space over place and a nomadic lifestyle. Whereas corporate narratives about the capacities of post-Fordist capitalism celebrate an epoch of space that overcomes distance as an obstacle to development and prosperity (Goldman \& Papson, 2011), texts like the Levi's Braddock campaign call for a rediscovery of place, a reseeding of the landscape that embraces, rather than rips out, rootedness. In this sense, the Braddock campaign attempts to relocate value in the context of a place. Listen, for example, to Jeb, an artistic migrant to Braddock, share his enthusiasm for having

The rare chance to sort of do something very unique and something that I was really sort of intrigued by which was the, the opportunity to sort of craft and shape a place, and, uh...pioneer, I suppose a neighborhood or a community that I think needed some, um, some assistance (emphasis added).

In other words, the Levi's campaign sought to wring out and extract value from Braddock as a specific place where community can be rekindled and neighborhoods revived. These are the very social forms that otherwise create a drag on capitalist development in an age where social, economic and political organization tends to be fluid, mobile and nomadic. The rediscovery of place coupled with the revaluation of human labor can be read as a counterattack against the triumph of space over place in the late capitalist era and, more importantly, as Levi's commitment to those who want to locate themselves in place again.

Levi's television ad entitled "Go Forth to Work" offers a romanticized narrative of Braddock. The opening scene harkens back to the Great Depression. A new day rises on Braddock: in a field adjacent to the city, a young man-his faithful dog next to him_-warms his hands over a campfire while watching a freight train slowly roll past. A montage unfolds of a city in disrepair mixed with scenes of its residents waking up to "go forth to work." A measured voiceover by a young girl narrates the rest of the ad with an account of the history of westward expansion by American pioneers. The juxtaposition of voiceover and visual scenes draws a parallel to Braddock's reinvention as a contemporary frontier. Though the scenic tour begins in ruin, this is, when said and done, a story of the resiliency of spirit. Set against a montage of construction laborers working to restore abandoned public buildings, the child sage offers this historical mythology coupled with spiritual wisdom:

"We were taught how the pioneers went into the West. They opened their eyes and made up what things could be. A long time ago, things got broken here. People got sad and left. Maybe the world breaks on purpose, so we can have work to do. People think there aren't frontiers anymore. They can't see how frontiers are all around us."

As a motivational discourse about pressing on through adversity, this is very nearly the stuff of Nike. Indeed, that is precisely where the subject of meaningful labor has been hiding all these years - in ads for athletic shoes that 
repeatedly allude to the benefits of hard work, disciplined bodies and the accomplishments of purposeful physicality. The Levi's ad seems to invoke a sense of spirituality, choosing to substitute the passive construction of "maybe the world breaks on purpose" for the active voice of the Occupy movement that we must confront the crises of capitalism. Mystifying the crises of capitalism as world spirit (a world that possesses purpose) throwing challenges in our way in order for us once again to prove ourselves, diverts attention from the contradictions of global capitalism that have left Braddock a blighted relic of heavy industrialization. Instead of pointing out that these new frontiers are the product of the uneven development of economic geographies, the ad valorizes a negative landscape as an emptied space (frontier) that affords a new opportunity for personal growth and capital accumulation. This message might have been more emotional and poignant in 2010 when viewed against the experience of collapsing housing markets and broad layoffs: from 2007 to 2010 the median family lost $40 \%$ of its net worth, and the situation was much worse for younger people.

Authentic individual subjectivity and its accompanying complexes of anxiety and alienation have been "displaced" in the postmodern era by the fragmentation of the subject (Jameson 1984). Where Braddock was once a site of industrial alienation, now it beckons as a site where authenticity can be found-by working the soil of an urban farm with one's hands; by rolling up one's sleeves to demolish and rebuild; by creating the conditions for an urban renaissance. Levi's Braddock campaign hails a totem group of individuals who it imagines feel disenchanted and fragmented, and who seek to rediscover themselves in the accomplishments of serving a community by raising food and building shelters and creating art or utility. In a sign economy the imagery of alienation is the essential precondition for authenticity. But while the visual representations of alienation are rendered in terms of a rustbelt aesthetic, the motivational alienation that the ad summons has more to do with a lifetime of disappointing consumer narratives. We suspect that the youthful social demographic that Levi's hails has grown weary of the fabricated authenticity claims that saturate the landscape of commodity consumption. This hipster imaginary is also hungry for experiences of community, experiences that have been sometimes negligible in a social world oriented around hyper-individuated commodity consumption. Though impoverished and materially struggling, Braddock is depicted as a place where individuals can engage in non-alienating social relations by submitting to the necessity of work, and thus re-rooting themselves in a place, in a community that fosters authentic relationships.

This campaign that seems to advocate a return to roots as the first step toward an authentic, meaningful existence is, however, merely disguising the underlying sign game. Indeed, the entire Braddock campaign rests on the premise that the intended audience of educated, urban middle-class twenty-somethings is alienated from the inauthenticity of consumer capitalism. The campaign hails these alienated spectators by using the very instruments of inauthenticity that brought about these disenchanted sentiments and from which these spectators seek to distance themselves. Put another way, the Levi's campaign tapped the same immaterial labor necessary to reproducing consumer capitalismthe spectator's interpretive labor that is necessary to the completion of sign values. Because the subject is Braddock, Levi's can hail a generation of consumers weary of a generally inauthentic and placeless sign economy about the satisfaction of committing to real labor. As it always has been, alienation and the promise of utopian possibilities form a shared couplet. The difference this time around is how Levi's articulates the value of alienation, for it does value alienation here, turning it into a visual totem around which future value (e.g., the value of feeling a connection to a community) can be visualized.

\section{Contested Signs}

As we have already observed, relationships between advertisers and viewers change over time- they have a history - as each round of experience leaves a trace. Particularly from the consumer side, the technological advent of social media has made it possible for a broad demographic of 18-34 to comment on the efforts of advertisers and marketers. From the blogging community, the Levi's campaign elicited mixed reactions. With titles such as "Leviß's Go Forth "We Are All Workers" Marketing Campaign: Aspirational Or Exploitative?" bloggers responded to the Levi's campaign with well-considered critiques. Some distrusted the encoding strategies that defined the campaign's look: the artsy, moody, over-aestheticized black \& white photography of Braddock signified to them a romanticized mythology of Braddock that better fit the Levi's narrative than that of Braddock. Representative of this critique were the following:

In their campaign, Levi's has romanticized the Depression era through their beautiful, moody black and white photography, 
and trivialized the experience of those who suffered through it in the process. By invoking the "Grapes of Wrath" metaphor, Levi's has implied that we are, as a country, facing similar hardships by linking those images with narratives and slogans like

"We are all workers" and "Go Forth to Work." [4]

"The ad in question is a genius melding of amnesiac musings, blue collar fetishism, and astoundingly brazen brand-name posturing (posted by Shaun)."

These reactions fed into a second criticism that this kind of romanticization diverts attention from Levi's own global production practices:

"The irony of Levi's romanticizing a working-class theme and setting - a sentiment shared by others who deride the brand for harboring a "sweatshop" culture in their own factories abroad- was not lost on online consumers." [5]

The following online comment from a Facebook page was cited in behalf of this interpretation:

I hate Levi's ads. They promote that there are frontiers here in America to conquer. Like they really give a crap. Go Forth... they say. Go forth and move all your manufacturing overseas, close factories here, lay of [sic] workers and try to still claim you care. They should be ashamed of themselves. -- Roger Cropley

This contestation effectively extended for some into a guerrilla sign war, such as this pointed commentary over a photo of a Levi's campaign billboard in Oakland. Applying a Derrida-like practice of erasure effectively establishes the tension between that which is deleted and that which is inserted.

Situating this semiotic contestation more explicitly within the political economy of globalized supply chain systems, a few linked the generalized critique of manufacturing outsourcing with subcontractors in Third World countries to specific charges against Levi's regarding environmental pollution, occupational health considerations, and the exploitation and repression of workers.[6]

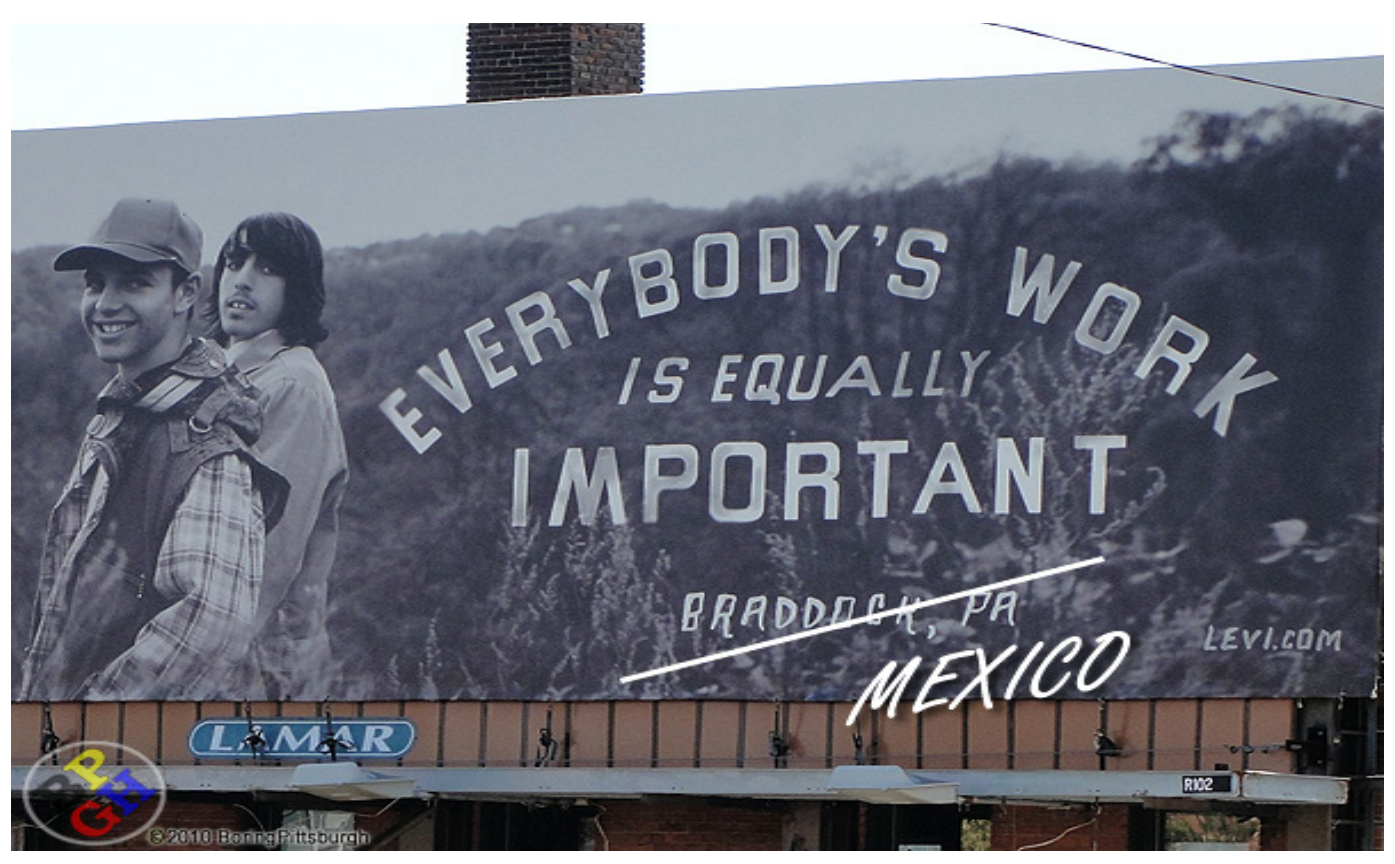

A deep current of cynicism runs through these discourses, so deep that few even comment on the shades of a subterranean Marx in Levi's slogans - "Everyone's Work Is Equally Important”_along with Marx's radical anthropology that humans make themselves in the act of making their world.[7] Cynicism also premises the harshest criticisms aimed at Levi's for being hypocrites_Levi's talks the talk by donating to Braddock's restoration efforts, but they certainly aren't bringing manufacturing jobs to this destitute place in the U.S.A. Though the impulse behind this criticism stems from an admirable sense of social justice, we wonder if this is not a critique forty years out of 
date, that wants to turn back the clock on the very logic of neoliberal globalization that explains the disappearance of jobs from Braddock. While these critics seem media savvy about consumer marketing strategies and are quick to expose the campaign's inconsistencies, their criticisms don't really theorize this political economy of signs in relation to a global capitalist context. They thus don't situate the Levi's campaign as a logical outcome of cultural capitalism. Slavoj Žižek explains that contemporary capitalism has evolved a tendency to view social responsibility as a series of exploitation offsets. Corporate marketing encourages the feeling that through the act of consumption "at the same time you fulfill a series of ethical duties.” The Levi's campaign fits Žižek's analysis to perfection.

Like the general media within which it is situated, the Levi's campaign tends to separate the effects of capitalism from a structural etiology of capitalism. Discourses about capitalism become turned into news accounts of scandals and accidents that are invariably framed in terms of individual human frailties of "greed" rather than the institutional logic of profit at any cost. The blame goes to individuals or to specific companies or to government rather than illuminating the structural contradictions of capitalism, thus insulating the unquestioned ideological faith in capitalist "free" markets.

Alongside these frames, as Žižek points out, cultural capitalism has evolved a semiotics of compensation, so that some brands wrap themselves in sign values that embrace philanthropy and ethics.

"[W] should probably distinguish between the two[8] phases of this "cultural capitalism," as exemplified by a shift in the logic of advertising. In the 1980s and 1990s, it was the direct reference to personal authenticity or quality of experience that predominated, without any direct ideological coloring, while, over the last decade, one can note the increasing mobilization of socio-ideological motifs (ecology, social solidarity): the experience referred to here is that of being part of a larger collective movement, of caring for nature and for the ill, the poor and the deprived, of doing something to help" (Žižek, 2010:356).

At this stage of cultural capitalism ethical consumption has developed into a potentially lucrative field of sign value. Such sign values are, however, poised on the knife-edge of a dialectical tension. Even though Levi's appeals to a desire for community and for meaningful labor seem to be the antipode of cynicism, they take shape in the same cultural cauldron. For some years now, a cynical attitude towards the mainstream of commodities has shaped notions of hipness. Within the so-called Millennial generation, the Hipster subcultures react with immediate scorn for conventional commodity signs, seeking instead to find, or rather rediscover, value in the esoteric, the offbeat, and the resistant. So, when Levi's represented Braddock as the antipode to all that has been previously defined as hip, they opened the door to hipness residing there. In capitalist terms, Braddock has been tapped out of value for decades, and it now lies at the edge of the garbage dump. But it is precisely here on the edge of the anti-hip that Levi's imagines a new landscape for individual expression, and thus Braddock is turned into a site for the new hipness - this is the "new frontier": a place where it might be hip to work with your hands and your back when no one else does anymore; hip to imagine yourself as a part of a community; hip to take the path less taken. All of this is folded into a second-order signifier, and its signifying value is linked to the brand sign.

An element of this hip cynicism is a fetishism of demasking. In this cultural context, ideological demasking or "throwing away the veils which are supposed to hide the naked reality" may not actually aim at "the liberating gesture of saying finally that 'the emperor has no clothes"' (Žižzek, 1989:25). Calling Levi’s out for its hypocrisy and inconsistencies offers a means for demonstrating that one is hip to reading commodity semiotics, and not easily fooled by the visual sleights-of-hand. The act of demonstrating that one is not subject to brand machines allows individual spectators to wax poetic against Levi's, Urban Outfitters, American Apparel or any other manifestation of retail Capital that hails a hip demographic, while the underlying structures, conditions and contradictions of global capitalism remain out of sight and off limits.

This is how the commodity-sign machine works. Once we understand this circuitry, it seems nearly impossible that inspirational and romanticized ad campaigns like this by Levi's will not further beget the reproduction of cynicism.

\section{| The Wolf Jigsaw Puzzle as Art}

To tie together two threads of recuperation and aura that run throughout the Braddock campaign, it is necessary to make explicit how Levi's, in addition to pointing to the city of Braddock as the object of recuperation and reinvention 
under the aura of memory and nostalgia, further intends to recuperate the loss of aura that surrounds manual labor. Susan Willis, in her analysis of Walter Benjamin's "The Work of Art in the Age of Mechanical Reproduction," narrates the dialectic of Benjamin's “'aura,' the concept Benjamin used to describe all the unique magical qualities of great traditional art” (1991:10). Benjamin recognized that the commodified mechanical reproduction of culturewhat came to be known as mass culture-had an erosive effect on the aura of bourgeois culture. While the fading of aura may indeed foster new opportunities "for a radically optimistic definition of mass culture" thanks to the "smashing" of traditional bourgeois meaning systems, on the flip side, "the forces of containment" are just as capable as subcultural forces of reappropriating signs with the intention of boosting sign values (1991:11-12). The deterioration of traditional meaning systems creates new avenues for redefining cultural artifacts, some with revolutionary potential, while others are put to the service of commodity sign production.

Whatever aura Braddock's working-class aesthetic has come to possess has been constructed retroactively. The difference between aura and myth has become hard to discern. It begins by referencing the dialectical between heavy industrial labor and its accompanying blue-collar, working-class culture that was mediated by the consumption of mass culture artifacts. In their day, Adorno and Horkheimer bemoaned the preconstituted conformism of massmarketed culture. At the height of an industrial working class culture, heavy-duty work wear became part of a functional workingman's uniform - this included Levi's, Ben Davis Work Wear, Dickies and Carhartt. Over the years, as the clothing shifted from work to leisure wear and the fabric became less durable (consumer obsolescence), and industrial jobs became scarcer, youth grew nostalgic for the classics-perhaps hoping that their substance signified an identification with a romanticized nobility of working-class labor.

In this sense, the aura of working class culture stems from the recombinant semiotics of the ironic subcultural aesthetics that have not only shaped, but also forged, the "aura" that came to be associated with blue-collar, manuallabor - such as that which has been appropriated by the Levi's campaign. To put it another way, irony and selfreflexivity has generated a pseudo-aura, a simulacrum of sorts, a post-mortem aura that some retailers have plucked from the debris of detached and discarded meaning systems. Benjamin began the discussion of aura as coterminous with traditional, modernist art and its concomitant bourgeois meanings, but recognized that it could be replaced with mechanically fabricated aura in the media spectacle. As such, ironic self-reflection is more likely found swirling about the pseudo-aura. In the context of the Braddock campaign then, the pseudo-aura that hovers around representations of blue-collar, manual labor or zip-code tattoos that signify pride of place in an inhospitable world become little more than a "work of art" for the purposes of sign value accumulation. Levi's takes the hip fetishization of workingclass signifiers to a new level, complete with hardcore ruin porn, lo-fi working-class tunes, combined with other features of the hipster aesthetic, like tattoo sleeves, to create a commodity sign campaign grounded in a pastiche of signifiers.

Simon Metcalf (2009) sketched out the complex genealogy of the wolf T-shirt as a hyperreal signifier in hipster subcultures, an adaptation that drew on the perceived kitsch of hypercommodified souvenirs-reproductions. Knowingly wearing such signs of trash culture, hipsters found in the cheesy wolf icon a sign that demonstrated the impossibility of equivalence to the real, and could thus be worn as a sly joke about a culture of commodity representation. So it becomes doubly interesting when Levi's camera comes to rest on an assembled jigsaw puzzle depicting a wolf pride framed as a piece of art and mounted on the wall of an indigenous working class family from Braddock. Here is the ultimate in the mechanical reproduction of art. Though certainly this could be interpreted as another adoption of kitsch, it seems here to represent an authentic sentiment of a family's cultural identity. It regains a non-ironic sense of aura - a sincere expression of a primitivist sensibility - a statement of defiance against both the vicissitudes of industrialization and the high priests of auratic art.

Including the framed wolf jigsaw puzzle in the depiction of Braddock's cultural identity is rich in selfcontradiction. It cuts to the heart of a tension in the ad campaign between the representation of a sincere pursuit of primitivist authenticity and the ironic pose that is associated with hipster culture (can authenticity be cheesy?). Obviously, hipster culture is contradictory by design; in this case, there is a dialectical tension between the motivated search for authenticity in moving to the crumbling ruins of Braddock (here we suspect the ruin porn fetish is less ironic than nostalgic), and the authentic cheesiness, paradoxical in and of itself, which is a defining feature of hipster culture. The Braddock working class family, in whose home the wolf puzzle appears framed as art, are not hipsters but they have embraced a primitivist aesthetic. So, does this represent simply an authentic preference for "poor taste" or has our culture reached the point where these signifiers have been subjected to so much irony and self-reflexivity (partly now attributable to hipster culture's interaction with commodity culture), that it has become increasingly 
difficult to separate feelings of genuine identity from self-reflexive, ironic constructions? Although this applies to only a handful of signs at the moment (wolves in this case), it is only going to expand and apply to more and more signs as they become increasingly coated in layers of ironic self-reflexivity. So, if this campaign begins from the premise that there has developed a legibility deficit, here it throws a wrench into the machine of legible meaning systems: the Braddock campaign largely appeals to people in a youthful demographic, who, armed with their semitheorized disenchantment with late capitalism, can't help but giggle knowingly at "the wolves" images.

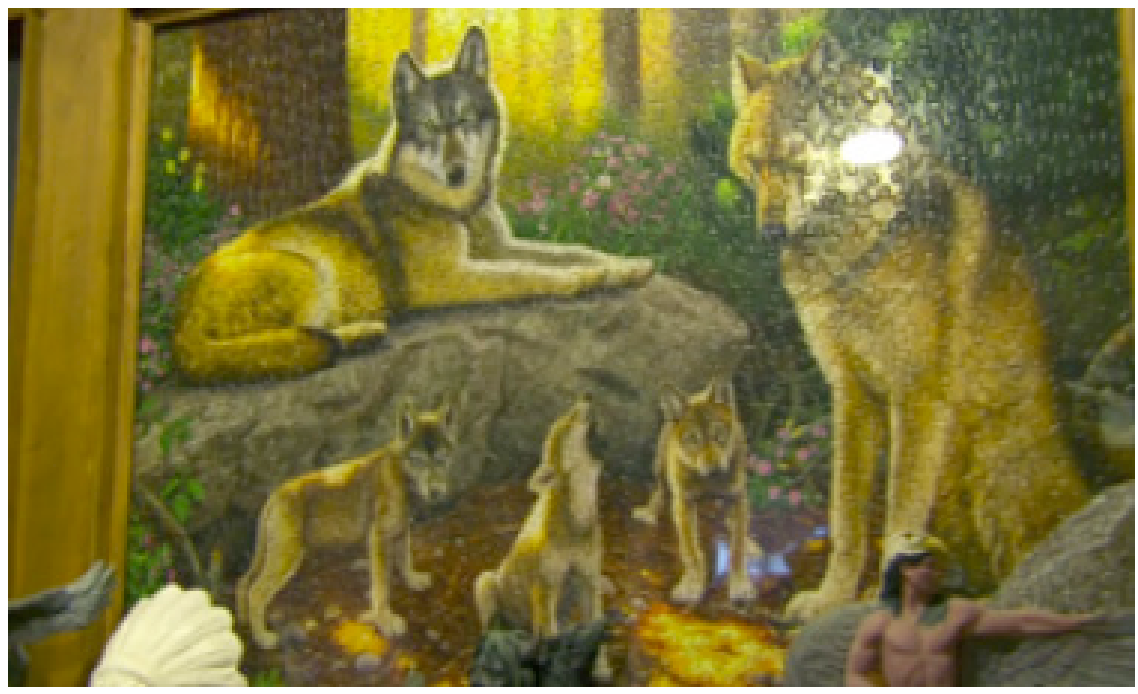

\section{The Cultural Politics of Cynicism in an Era of Capitalist Semiotics}

Franco Berardi (2009) used the term semio-capitalism to describe the stage of capitalism devoted to the endless reproduction of brand values - commodity-sign values. It is a stage characterized by the maturation of the "structural law of value." Advertising, in particular, in the latter half of the 20th century became an engine of semiotic recombination, always aimed at turning commodities as objects into commodities as signs. If, following Harvey (1985), the secondary circuit of capital is real estate, we might also conceptualize a tertiary circuit of capital as this system of recombinant semiotics devoted to the endless reproduction of commodity signs. The fate of Braddock as seen in its remains might be interpreted as a kind of testament to Baudrillard's assertion that a shift toward the structural law of value coincided with the beginning of the "end of production." Rather than locate the structural law of value as marking the "end of production" (though it could easily be mistaken for it), we see it as marking the shift from one production regime to another-from the production of goods to the production of signs. The circuitry of semiotic capital has become central to bolstering a regime of globalized production dependent on attaching a circuitry sign/brand/sign (S-B-S) to commoditized goods and services.

Today, nearly four decades after deindustrialization began we see a nearly abandoned, broken down, decomposing steel town, while the sign scape pays homage to the nitty-gritty of ruin porn. Though less glamorous than the ruin porn of Detroit born out of the stately bourgeois architecture of early modernism, Braddock's more modest ruin porn speaks to the possibility of a restoration of spirit. The ad draws what seems to be a stark contrast between the soullessness of shiny consumer capitalism, and this discarded place that consumer capitalism has left behind. In the cultural geography of Levi's Braddock the human spirit can again soar because it can again find purpose in itself -in its immediate exercise of labor. The spirituality of this labor is made symbolically evident by the installation of the stain glass window in the community building that is being restored.

The regime of sign production renders superfluous distinctions between production and consumption in the value articulation process. This is because a necessary form of labor in this process is the unpaid interpretive labor performed by viewers - spectators and consumers. Because this is truly an endless process - the machinery of sign production can never rest-various degrees of interpretive alienation have settled like a cloud over recent generations. The so-called hipster generation is best known for the way they wear their alienation from signs-like 
the punks who preceded them they intentionally mismatch the signs of consumerism that have come and gone, embracing tackiness and kitsch in ways that would make Celeste Olalquiaga green with envy. Above all, hipster cultures pivot on an aesthetic sensibility that is profoundly uncomfortable with the commodification of signs. To this extent, the knowing hipster is always prepared to abandon particular aesthetic preferences once they catch on and become appropriated by others. Many of the affectations that have become associated with hipsters involve an ironic fetishization of formerly working class signifiers-e.g., PBR, the kitsch animal T-shirt, or the tattoo sleeve. Whereas Norman Mailer's "white negro hipster" fetishized blackness in the post World War II era, the contemporary hipster fetishizes proletarian lifestyles.

In practice, capital flows give rise to uneven development with capital flowing to where investors perceive the potential for the highest returns on investment. This process overweights capital in some sectors while ignoring others; over time, where capital has become oversaturated the tendency for the rate of profit to decline ensues, and the previously ignored sectors_capital vacuums-become more appealing as investment sites. In the secondary circuit of capital this takes the spatial form of gentrification - as capital flows into areas that seemed to have been exhausted by previous development. In the tertiary circuit of capital, sign reproduction similarly invades those consumer goods from the past whose meaningfulness appears to be exhausted. Hipsters circa the millennium have performed what we shall call semiotic gentrification. Think of it as a semiotic rent gap. Ever aware of the fraud of value in the epoch of the simulacrum, hipsters function as ironically self-aware commodity bricoleurs who have been able to regenerate sign values for consumer goods whose values had been exhausted.

In the circulation of signs, where material signifiers have been worn out and consigned to thrift shops-it is here that the highest return on semiotic investment is possible. It is ironic that hipsters (who often seem ambivalent about their attachment to capitalism) have been notable as part of a creative class that has taken advantage of both the gentrification of urban spaces and the spaces of sign circulation (axes of class and status respectively). In fact, the spaces of gentrification and the spaces of sign revival overlap substantially, both conceptually and materially.

\section{| Landscapes of Ruin and Discourses of Commodity Fetishism}

The Levi's televisual campaign was anomalous in that it reintroduced the material premise of history-that is, that the meaning of place has both a before and after, rather than the eternal now of the spatially abstracted image. In fact, the campaign actually invokes the past as a referent, evident in the primacy of landscapes of ruin. But even with these referential traces, this is mostly a past without a motivated history. Though these are landscapes of capitalist ruin, and the visuals are faithful to the task of recording the absence of Capital (which is relatively easy since, after all, Capital has run off elsewhere in the global system) the advertising narrative makes no note of Capital whatsoever, nor its practices. It is not just invisible, it is also a narrative, or conceptual, absence.

The Levi's campaign builds off the contradictions within the capitalist system, but in a not-quite-straightforward way. It is not uncommon for advertisers to appropriate a hot subcultural trend or look. And Levi's does try to appropriate subcultural signifiers from youth subcultures, but they do something more: the Levi's campaign exemplifies how the tragedy of capitalist development can be turned into a repository of sign values. Braddock represents the collateral damage that follows from the logic of capital disaccumulation in the era of globalization. As a signifier of disrepair, however, Braddock is quietly separated from the conditions of a political economy that produced it, while finding a new home within the political economy of consumer sign-values. Perhaps this is further indication of a cultural shift that defines the postmodern as the cultural logic of late capitalism, wherein signs that would otherwise signify obstacles to capitalist accumulation actually constitute resources for capitalist accumulation.

Critiques of advertising by Williamson (1978) and Ewen (1976) demonstrated that $20^{\text {th }}$ century advertising routinely turned attention from production relations to relations of consumption. Commodity fetishism distills out all traces of production, making it seem as if commodities spring de novo from the signs that circulate about them. At first glance, the Levi's campaign seemed unwilling to countenance the discourse of commodity fetishism. True, the Levi's campaign situates the value of work front and center on the screen, but it nonetheless manages to conceal the social relations of commodity production for the product being advertised (jeans). In part, it does so by severing the relationship between place and space in the contemporary capitalist universe of globalization. Fredric Jameson wrote in his essay on the "Cultural Logic of Postmodernism" that

Appropriately enough, the culture of the simulacrum comes to lifein a society where exchange-value has been generalized to 
the point at which the very memory of use-value is effaced, a society of which Guy Debord has observed, in an extraordinary phrase, that in it 'the image has become the final form of commodity reification' (The Society of the Spectacle) (Jameson, 1984:65).

Times change. In the Levi's campaign we bear witness not to the total effacement of "the memory of use value" but rather to its nostalgic resurrection in this visually post-apocalyptic landscape of capitalist ruin. Indeed, what Levi's has artfully accomplished is to situate the sign of Levi's in relation to stylized signs of use-value, labor and meaning. And in this way, Debord's prophecy rings more true than ever. It is not accidental that the material good (the jeans) is essentially on holiday in this TV campaign because the real product being produced here is the commodity sign - in this case it is the sign of work. So while our attention has been directed toward the immediate value of labor and a world free of commodity fetishism, the ad not only reifies the commodity, it also conceals the labor required to produce the sign, and in fact turns work into a sign of itself.

The signifieds of work and use-value are turned into second-order signifiers of a Levi's Ethos. Conjuring up memories of use value and labor is not just about nostalgia, these are also offered as a hyperreal remedy to the crisis of meaning prompted by swimming endlessly through the circuitry of the simulacrum. Signs of labor and usevalue as a hyperreal tonic? Do the signs of labor and use-value combat the hyperreal or reproduce it? Maybe it's not an either-or? But one does have to wonder whether rather than combating commodity reification, if reviving the signifieds of labor and use value may actually steer towards reproducing a blindspot about commodity reification, so that media culture can go on separating cultural capitalism from the system that organizes the conditions of production in factory towns in Haiti, Soweto, Mexico, Turkey and Taiwan.

\section{Endnotes}

1. See Robert Goldman and Stephen Papson, Sign Wars, for an extended analysis of this semiotic contestation.

2. Richard Sennett has made compelling arguments about the gradual historical disappearance of the career as either a route toward upward mobility or personal satisfaction.

3. Not to be confused with the 1960 s use of this term by SDS.

4. (http://mprcenter.org/blog/2011/02/16/levis-gofo rth-and-exploit-part-1/)

5. (http://www.localspeak.com/blog/93/levis-goforthwe-are-all-workers.html).

6. Christopher Lehmann, The Big Levi's Lie Campaign | The Awl http://www.theawl.com/2010/06/rich-people- things-the-big-levis-lie-campaign, June 28, 2010. (http://boringpittsburgh.com/boring-pittsburgh/ levis-braddock-pa-ad-campaign/. See alsoLawrence Delevingne, "Gap And Levi Strauss Are Poisoning African Children," http://articles.businessinsider. com/2009-08-11/green_sheet/30038146_1_lesothogap-dangerous-waste.

7. Kathy Newman, http://workingclassstudies.word press.com/2010/10/17/levis-braddock-exploitationor-visibility/

8. Actually we see this as a third phase of "cultural capitalism" rather than the second. Žižek skipped over the glossier first phase of commodity sign assembly (the late 1960s to the early 1980s) during which authenticity was not yet a concern and the quality of experience was generally an airbrushed abstraction.

\section{References}

Baudrillard, Jean. 1981. For a Critique of the Political Economy of Baudrillard, Jean. 1993. Symbolic Exchange and Death. Sage. the Sign. Telos Press.

Baudrillard, Jean. 2005 (1968). System of Objects. Verso. 
Benjamin, Walter. 1969. "The Work of Art in the Age of Mechanical Reproduction,” pp.217-251 in Illuminations. Schocken.

Berardi, Franco. 2009. The Soul At Work: From Alienation to Autonomy. Semiotexte.

Brenner, Robert. (2004) "New Boom Or New Bubble? The Trajectory of the US Economy," New Left Review. 25 (January February):57-90.

Debord, Guy. 1970. Society of the Spectacle. Red \& Black Press.

Delevingne, Lawrence. 2009. "Gap And Levi Strauss Are Poisoning African Children," http:// articles.businessinsider.com/2009-08-11/ green_sheet/30038146_1_lesotho-gap-dangerous-waste.

Derrida, Jacques. 1981. "Interview with Julia Kristeva," in Positions. University of Chicago Press.

Ewen, Stuart. 1976. Captains of Consciousness: Advertising and the Social Roots of Consumer Culture. Basic Books.

Goldman, Robert and Papson, Stephen. 1991. "Levi's and the Knowing Wink," Current Perspectives in Social Theory, 11:69-95.

Goldman, Robert and Papson, Stephen. 1996. Sign Wars. Guilford.

Goldman, Robert and Papson, Stephen. 1999. Nike Culture: The Sign of the Swoosh. Sage.

Goldman, Robert and Papson, Stephen. 2011. Landscapes of Capital. Polity.

Hardt, Michael and Negri, Antonio. 2000. Empire. Harvard University Press.

Harvey, David. 1985. The Urbanization of Capital. Oxford University Press,

Haug, Wolfgang Fritz. 1986. Critique of Commodity Aesthetics: Appearance, Sexuality, and Advertising in Capitalist Society. University of Minnesota Press.

Jameson, Fredric. 1984. "Postmodernism, or, The Cultural Logic of Late Capitalism” New Left Review, July-August, 176:53-92.

Kellner, Douglas. 2005. Media Spectacle and the Crisis of Democracy. Paradigm.
Lehmann, Christopher. 2010. The Big Levi's Lie Campaign | The Awl. http://www.theawl.com/2010/06/rich-people-thingsthe-big-levis-lie-campaign, June 28, 2010.

“Levi's Go Forth 'We are all Workers' Marketing Campaign: Aspirational or Exploitative?” (http://www.localspeak.com/ blog/93/levis-go-forth-we-are-all-workers.html). August 9, 2011.

“Levi's Opens Jeans Factory in Braddock, PA?" 2010. http:// boringpittsburgh.com/boring-pittsburgh/levis-braddock-paad-campaign/ July 5 .

Metcalf, Simon. 2009. "Postmodern Uncertainty and the Fluctuation of Meaning: Apathy, Authenticity, and Identity in Hipster Subculture," Senior Thesis, Lewis \& Clark College.

Newman, Kathy M. 2010. "Levis \& Braddock: Exploitation or Visibility?" http://workingclassstudies.wordpress. com/2010/10/17/levis-braddock-exploitation-or-visibility/

Olalquiaga, Celeste. 1992. Megalopolis. University of Minnesota Press.

Rutledge, Pamela and Buckner, Bonnie. 2011. "Levis: Go Forth and Exploit, Part 1," The Media Psychology Blog, http:// mprcenter.org/blog/2011/02/16/levis-go-forth-and-exploitpart-1/ February 16.

Sennett, Richard. 2007. The Culture of the New Capitalism.

Trudell, Craig and Keith Naughton, "Clint Eastwood Heralds Comeback in Detroit With Chrysler's Super Bowl Ad," Feb 6, 2012. http://www.bloomberg.com/news/2012-02-06/ eastwood-calls-halftime-in-america-in-chrysler-super-bowlad.html

Williamson, Judith. 1978. Decoding Advertisements. Marion Boyars.

Willis, Susan. 1991. A Primer for Daily Life. Routledge.

Žižek, Slavoj. 1989. The Sublime Object of Ideology. Verso.

Žižek, Slavoj. 2010. Living in the End Times. Verso. 
